\title{
Some New Insights into Trade Potential between the EU and Its Mediterranean Partners
}

\author{
Nicolas Péridy \\ UFR Sciences Économiques et de Gestion, Université du Sud Toulon-Var (LEAD), Avenue de l'Université, \\ BP 20934, 83957 La Garde Cedex, France \\ Correspondence should be addressed to Nicolas Péridy, nicolas.peridy@univ-tln.fr
}

Received 22 March 2012; Accepted 3 May 2012

Academic Editor: Almas Heshmati

Copyright (๑) 2012 Nicolas Péridy. This is an open access article distributed under the Creative Commons Attribution License, which permits unrestricted use, distribution, and reproduction in any medium, provided the original work is properly cited.

This paper provides new insights into the calculation of trade potential between the EU and its Southern and Eastern Mediterranean partners (MPs). It is based on an econometric specification which takes into account some new explanatory variables which are not included simultaneously in the previous studies. These include trade costs (tariffs, NTBs, and logistics costs), factor movement (migration and FDI), as well as governance. In addition, specific estimators are implemented in order to account for zero trade flows, endogeneity and dynamics. The main conclusion of this study is that contrary to some results found in previous studies, MPs have reached their export potential with the EU. It is also shown that there is no specificity of the MP-EU trade potential in comparison with the other main PTAs (NAFTA, MERCOSUR, and ASEAN) which have also reached their trade potential. These results have strong policy implications.

\section{Introduction}

Almost 50 years after the conclusion of the first trade agreements between the EU and its Mediterranean partners (MPs) and 15 years after the implementation of the Barcelona agreement $^{1}$, there is still a debate concerning the actual effects of these agreements on trade. In this regard, although ex-ante studies concluded to the existence of significant potential gains of the EuroMed agreements, ex-post analyses reveal that these agreements had only limited effects (for a recent survey, refer to [1]). This result can be explained by various reasons. First, the shallow integration between the EU and MPs remains unachieved because tariffs applied by MP countries to EU imports are not yet fully removed despite the Barcelona agreement. In addition, the lack of deep integration is a second reason which explains the small effects of the EuroMed partnership. This is due especially to persistent protection in agriculture in the EU, the presence of significant nontariff barriers (NTBs) in MPs, restrictive rules of origin as well as the lack of service liberalization. A third set of reasons includes the slow integration process across MP countries (horizontal integration), the type of trade specialization (which often relies on low value-added products), as well as the innovation gap between the EU and MP countries, which may be an obstacle to growth, convergence, and trade. Finally, the lack of democracy in MPs can also be suspected to restrain FDI, trade and growth in these countries.

Given these mixed effects of the EuroMed partnership on trade between MPs and their EU partners, the question is to know whether there is still a significant trade potential between these two areas. If so, this means that the EuroMed agreements have failed to produce a fully integrated area between the EU and its Southern partners. Conversely, if the trade potential is no more significant, this suggests that the trade intensity is normal between these two areas. In this case of course, the policy implications will be different with regard to upcoming trade and other economic negotiations involving the EU and MPs.

In this regard, the existing research studies generally conclude that MPs' export potential toward the EU is significant but of limited magnitude. For example, Péridy [6] shows that MPs' observed exports to the EU are about 10-20\% lower than exports expected (fitted) by the model (depending on the econometric specification). Some exceptions concern 
Lebanon and Jordan, for which the export potential is greater (about 30-50\%). Some other studies provide similar results. For instance, Lee and Gohar [7] show limited evidence of export potential, except concerning exports of agricultural products. This research has also been extended to the Gulf Cooperation Council (GCC) or GAFTA. It is shown that trade potential between GCC countries on the one hand and the EU and the US on the other hand is also limited [8]. It is also shown that trade potential across GAFTA countries, though significant, is also restricted, especially when the exporting country is oil producer [9]. This is mainly explained by the lack of complementarity in the trade structure of GAFTA members.

Hence, although the existing literature provides some insights into trade potential between the EU and MPs, the present paper aims to go further in this analysis by including several new contributions. First, it is based on a comparative analysis which makes it possible to compare the MP-EU trade potential in the recent period (20002009) with that corresponding to other trade groups, such as NAFTA, MERCOSUR, as well as ASEAN.

Second, it is based on new gravity models which follow Anderson and van Wincoop [10] by explicitly including trade costs, that is, tariffs, NTBs (in ad-valorem equivalents, AVEs) but also logistics performance indexes (LPIs) as a measure of transport costs [3].

Original key variables are also introduced, especially factor movements, such as bilateral migration flows as well as bilateral FDI. Indeed, the new trade theory generally states that in an imperfect competition framework, international trade itself fails to achieve factor price equalization (FPE) $[11,12]$. As a result, other factor movements such as labor or capital flows are required to achieve FPE. Hence, modeling trade flows cannot disregard migration and FDI, which are explicitly included in our model.

Governance is the final additional key variable which is also accounted for in this model. This variable seems particularly crucial in the context of the Arab Spring. In this regard, a large set of political indicators will be tested (rule of law, corruption, political stability, etc.) based on Kaufmann et al. [5].

Basically, taking these additional variables into account makes it possible to reduce the bias due to omitted variables which is commonly found in the existing research studies. This bias may lead to underestimate exports' fitted values and thus to overestimate trade potential.

As a final contribution, the econometric modeling relies on recent and specific estimators which are designed to correct the most important biases in the estimation of export potentials. For example, the estimation of country and timespecific effects makes it possible to capture the remaining omitted variables. In addition, the endogeneity bias can be addressed through the use of specific IV estimators, such as the Hausman and Taylor or other estimators described in Baltagi and $\mathrm{Wu}$ [13] and Greene [14]. The problem of zero flows can also be addressed by a specific estimator (Heckman two steps) which addresses the selection bias. Besides, specific estimators corrected for heteroskedasticity and autocorrelation will be presented. Finally, the model will also take dynamics into account through the generalized method of moments (GMM) estimator.

The final objective is to calculate reliable values of export potential while explaining properly trade patterns within the EuroMed area. The results are expected to have significant policy implications, not only concerning directly trade potentials, but also through the sign and the magnitude of the key variables in the model. In particular, the relationship between trade flows on the one hand and migration and FDI on the other is of crucial importance. In other words, are migration flows and FDI trade creating or trade diverting? In addition, is the persistence of NTBs so detrimental to trade? Does logistics performance significantly matter for explaining trade in the EuroMed area? What is the impact of governance? Are corruption and the lack of economic freedom actually trade reducing? If so, to what extent?

This paper is organized in the following sections. Section 2 develops the econometric model, including the theoretical underpinning, the model specification, the data and sources, as well as the choice of the appropriate estimators and the econometric testing. All technical details will be left in the Appendix. Results are presented in Section 3 whereas the policy implications are discussed in Section 4.

\section{Calculating Trade Potential from New Gravity Models: Some Methodological Issues}

This section is dedicated to the calculation of trade potential through new developments in gravity models. The model specification, data, and sources will be presented first (Subsection 2.1), leaving all technical details in the Appendix, including the theoretical underpinning of the model. Then, the choice of the estimators and the problems related to econometric biases will be discussed. The final subsection presents the methodology implemented for the calculation of trade potentials

2.1. Model Specification, Data, and Sources. The model used here is based on new developments in gravity models. From a theoretical point of view, the gravity equation has been considerably renewed in recent years. Indeed, it has been increasingly recognized that this equation can be derived from various international trade theories, notably Ricardian, Heckscher-Ohlin, and monopolistic competition models [15-17], but also the reciprocal-dumping model [18].

The most popular recent specification of the gravity model can be found in Anderson and van Wincoop [10]. These authors develop a consistent general theoretical framework with special emphasis on trade costs from which the gravity equation can be derived. In this framework, exports from country $i$ to country $j$ depend not only on the traditional gravity variables, that is, GDP and bilateral distance, but also on bilateral and multilateral trade costs (see the Appendix for a detailed description). The advantage of this specification is that it reduces the bias due to omitted variables through the specific inclusion of trade costs. This is a major advantage for the calculation of trade potentials which are based on the residuals of the model. 
In spite of this advantage, the model proposed here goes further by including additional variables. A first set of variables is related to factor movement, that is, migration and FDI. In the traditional trade theory, international trade itself ensures FPE. As a result, there is no international factor movement and thus, the trade equation does not include labor and capital. However, the recent trade theory suggests that in an imperfect competition framework, trade itself cannot ensure FPE. Factor movements are thus required in order to achieve it. Consequently, trade cannot be explained independently from labor and capital movements. This is why migration and FDI are included in our model specification. Trade in services is also added in the final specification, as trade in goods is expected to be complemented by trade in services (e.g., transport services are necessary for trading goods).

As last crucial variable, political factors are also expected to play a significant role in international trade. In particular, the lack of democracy is suspected to restrain trade flows as well as growth in these countries. In this regard, the recent political events in MP countries provide a good opportunity to test the impact of these political factors on trade. Interestingly, the recent literature has made considerable progress in the measurement of political issues and governance, especially with the World Governance Indicators database [5]. This makes it possible to measure three aspects of governance: the process by which government are selected, monitored and replaced; the capacity of the government to effectively formulate and implement sound policies; the respect of citizens.

Finally, the gravity model can also include a dynamic component. In other words, current exports also depend on past exports. This dynamic feature has its own theoretical justification, based on the existence of sunk costs [19]. Indeed, as firms must face significant sunk costs when entering the export market, they must first ensure that they will be able to amortize these costs. As a result, a firm which starts exporting is likely to go on exporting in the coming years. This is why the level of current exports is partly explained by the past level of exports.

Taking into account the variables described above leads to the final specification of the model as follows:

$$
\begin{aligned}
\log X_{i j t}= & a_{0}+a_{1} \log \mathrm{GDP}_{i t}+a_{2} \log \mathrm{GDP}_{j t}+a_{3} \log \mathrm{TAR}_{i j} \\
& +a_{4} \log \mathrm{NTB}_{i j}+a_{5} \log \mathrm{LPI}_{i}+a_{6} \log \mathrm{LANG}_{i j} \\
& +a_{7} \log \mathrm{REG}_{i j}+a_{8} \log \mathrm{COL}_{i j}+a_{9} \log \mathrm{MIG}_{i j} \\
& +a_{10} \log \mathrm{FDI}_{i j}+a_{11} \log \mathrm{SERV}_{i j}+a_{12} \log \mathrm{POL}_{i} \\
& +a_{13} \log X_{i j t-1}+\alpha_{i}+\beta_{j}+\varphi_{t}+\varepsilon_{i j t},
\end{aligned}
$$

where $X_{i j t}$ denotes exports from country $i$ to country $j$ at year $t$. $\mathrm{GDP}_{i t}$ and $\mathrm{GDP}_{j t}$, respectively, reflect GDP in country $i$ and $j$. Trade costs are captured by three distinct variables: bilateral tariffs $\left(\mathrm{TAR}_{i j}\right)$ charged in country $j$ to products originating from country $i$; NTBs, in ad-valorem equivalent, applied in country $j$; transport costs, which can be captured by logistics performance indexes (LPI). LANG $i j$ captures the existence of a common language between the two partner countries. $\mathrm{REG}_{i j}$ and $\mathrm{COL}_{i j}$ relate to regional integration and colonial links, respectively; $\mathrm{MIG}_{i j}$ and $\mathrm{FDI}_{i j}$ correspond to factor movement, that is, bilateral migration and FDI. $\mathrm{SERV}_{i j}$ corresponds to bilateral trade in services. Finally, $\mathrm{POL}_{i}$ reflects the quality of political factors in the exporting country.

The full description of data and sources related to all variables are described in Box 1 . The equation is estimated over the recent period (2000-2009) for a matrix of 67 countries, of which: the EU-27 countries, nine MPs (Algeria, Morocco, Tunisia, Turkey, Egypt, Jordan, Syria, Lebanon and Israel), NAFTA and MERCOSUR (including Chile), the ASEAN+4 group, that is, ASEAN, China, Japan, Korea, India, as well as Gulf countries, Australia, Norway, Switzerland and South Africa. These 67 countries account for more than $80 \%$ of world trade. This is a reasonable basis for the creation of the antimonde which will be used for the calculation of trade potentials. Overall, the total number of observations amounts to 44,890 by taking into account the bilateral country dimension as well as the time period.

Some descriptive statistics can be provided concerning specific variables in this model. Starting with NTBs, Figure 1 shows that the average equivalent (AVE) of NTBs amounts to about $40 \%$ in Algeria, Egypt, and Morocco.

Turning to the logistics performance, the recent World Bank study [3] reveals that MENA countries are far away from international standards in this area. As a matter of fact, Figure 2 exhibits the country ranking in the EuroMediterranean area. It is striking to observe that over a total of 155 countries, there is a huge gap between on the one hand EU countries, which are amongst the most efficient in the world and MENA countries on the other hand which are generally much below the world average, especially Libya and Algeria which are at the bottom of the list.

Some countries have recently made real efforts. In particular, by developing "Tanger Méditerranée" with accompanying road and other infrastructure developments, Morocco should significantly go up in the list in terms of country ranking. However, similar efforts should be made in other countries in order to increase the efficiency and the competitiveness of their trade. For these countries, as suggested by Figure 3, particular efforts should be made toward improvement of the efficiency of the clearance process regarding customs (and other border agencies), the quality of transport, and IT infrastructure for logistics, the efficiency in tracing and tracking international shipments, as well as the competence of the local logistics industries.

Turning to governance, Kaufmann et al. [5] have proposed several indexes. In this regard, it is striking to observe that most MENA countries show an average below 0 , which reflect a poor performance in the governance process, especially in Syria, Algeria, Lebanon, but also Egypt, Morocco, and Tunisia to a lesser extent. The recent riots observed in these countries are obviously related to the poor quality in governance. In particular, significant efforts should 
(i) Bilateral exports are measured in constant PPP; source: UNCTAD (Comtrade database)

(ii) GDPs are measured in constant PPP; source: Cepii (Chelem database)

(iii) $\mathrm{TAR}_{i j}$ is captured by the applied weighted average tariffs charged on the importing country $j$; source: World Bank (World Development Indicators). As a sensitivity analysis, the Market Access Overall Trade Restrictiveness Indexes (MAOTRI) captures the barriers faced by each exporter when selling in other countries; source: Kee et al. (2008), [2].

(iv) NTBs are proxied by ad-valorem equivalents (AVEs) calculated in Kee et al. [2]. The methodology is fully described in the Appendix.

(v) $\mathrm{LPI}_{i}$ is a larger proxy than transport costs; this indicator is built from the information gathered in a worldwide survey of the companies involved in logistics services. Seven areas are covered by this index, namely: efficiency of the clearance process by customs and other border agencies, quality of transport and information technology infrastructure for logistics, ease of arranging international shipments, efficiency of the local logistics industry, ability to trace and check international shipments, domestic logistics costs, as well as timeliness of shipments in reaching destination. The LPI is a weighted average of these variables. It ranges between 1 (worst) to 5 (best); source: World Bank [3]

(vi) $\mathrm{LANG}_{i j}$ is a dummy variable which takes the value of 1 if a common language is spoken by at least $10 \%$ of the population in each country pair (exporter and importer) and 0 otherwise; source: Cepii (Chelem database).

(vii) $\mathrm{COL}_{i j}$ reflects colonial relationships over a long period of time with substantial participation in the colonized country's governance. This variable is equal to 1 in case of colonial links and 0 otherwise. It accounts for cultural and historical relationships which are expected to increase trade flows between some EU countries and Mediterranean countries. Source: Cepii (Chelem database).

(viii) $\mathrm{REG}_{i j}$ (Regional integration) is proxied by a bilateral dummy; source: WTO (RTA database)

(ix) $\mathrm{MIG}_{i j t}$ is measured by the bilateral migrant stock in country $i$ originating from country $j$; as a sensitivity analysis, it is measured both in value and as a percentage of the exporting country's population; source: World Bank (Bilateral Migration and Remittances 2010)

(x) $\mathrm{FDI}_{i j}$ is captured by several proxies: inward and outward bilateral stock or flows (in value and as a percentage of GDP); World Bank (World Development Indicators); UNCTAD (Handbook of Statistics and World Investment Report).

(xi) SERV $_{i j}$ is measured by trade in services (source: UNCTAD [4])

(xii) $\mathrm{POL}_{i j}$ is captured by several alternative proxies: voice and accountability, which measures to what extent citizens are able to participate in selecting their government, political stability and the absence of violence and terrorism, government effectiveness, regulatory quality, rule of law as well as the control of corruption (for more details, refer to [5]).

Box 1: Data and sources.

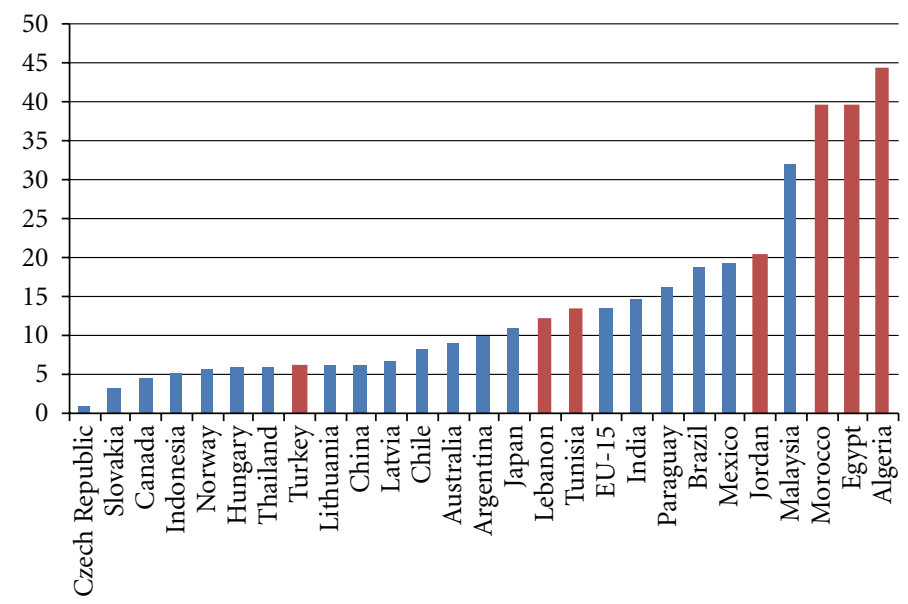

FIgURE 1: NTBs in MP countries: a comparison with selected other countries (average in tariff equivalent, \%) Source: Kee et al [2].

be made concerning especially (i) "voice," which measures to what extent citizens are able to participate in selecting their government (Syria, Tunisia, Egypt, Algeria, but also Jordan, and Morocco); (ii) political stability (Lebanon, Israel, Algeria, but also Turkey and Egypt); (iii) the control of corruption (Syria, Lebanon, and so forth); (iv) the rule of law, government effectiveness and the regulatory quality should also be improved, particularly in Algeria, Syria, and Lebanon.
Looking finally to education, in spite of real efforts recently undertaken in some MENA countries, the gap is still large with emerging or developed countries, especially the EU in terms of education and research, as shown in Figure 4.

To sum up, looking at some key variables of this model, there seems to be a significant gap between the EU on the one hand and Mediterranean countries on the other. This gap can be expected to have a significant impact of the growth 


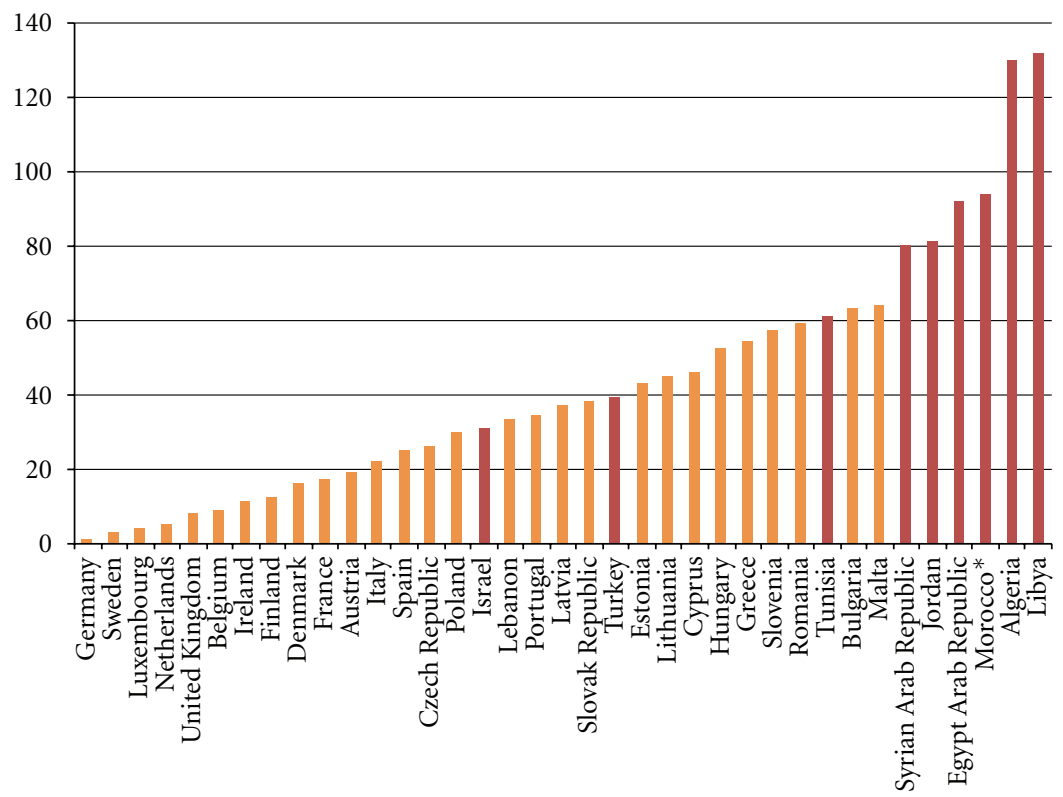

FIgURe 2: Country ranking for the Logistics Performance Index (rank 2010* over 155 countries) Source: World Bank [3]; *year 2007 concerning Morocco.

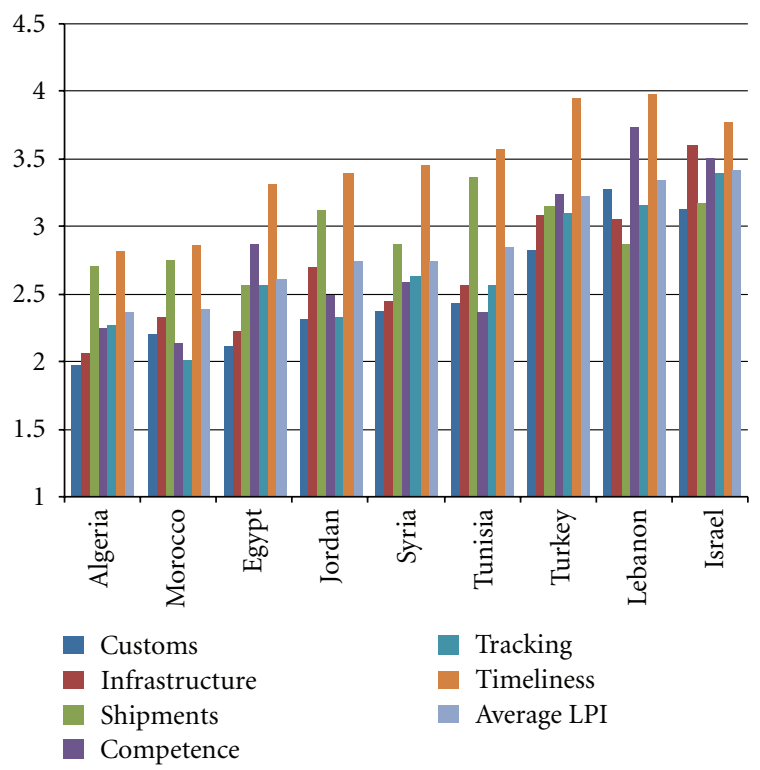

Figure 3: Logistics Performance Index (breakdown by categories) Source: World Bank [3]; * year 2007 concerning Morocco.

differential between these two areas, as it will be checked below.

2.2. Selecting the Appropriate Estimators. The selection of the appropriate estimators is guided by the potential econometric biases which may reduce the relevance of the calculation of export potentials. The first potential bias concerns heterogeneity which is commonly found in panel data models. This problem can be addressed through the inclusion of country and time specific effects, which capture heterogeneity across countries and time. It also addresses the problem of the remaining omitted variables [20]. These specific effects can be considered as fixed or random depending on the final specification of the model. In this regard, the calculation of Wald tests enables us to check that they are very significant.

A second problem concerns time invariant variables, whose parameter cannot be estimates through fixed-effects (FE) estimators, as well as endogeneity. This problem can be solved through the use of the fixed-effects vector decomposition (FEVD) estimator developed by Plümper and Troeger [21]. This three stage fixed-effects model makes it possible to produce efficient and less biased parameters of timeinvariant variables compared to random effects models, while dealing with the endogeneity problem ${ }^{2}$. However, the use of this estimator has been recently questioned in the literature [22].

An alternative estimator also makes it possible to simultaneously address the problem of endogeneity and the time-invariant variables. This is the Hausman and Taylor estimator, described in Egger [20]. This is a 2SLS random effect model which makes it possible to deal with potential correlation between the unobserved bilateral effects and some of the regressors. Moreover, it provides an estimation of time-invariant parameters and is suitable for out-of-sample prediction (see additional details in the Apendix).

A final potential bias concerns zero observations for the bilateral export variable. Zero flows are commonly found in gravity model. The simplest way to deal with this problem consists in estimating (1) with a transformed export variable:

$$
\ln X_{i j t}^{*}=\ln \left(X_{i j t}+1\right) .
$$

Indeed, when $X_{i j t}=0, X_{i j t}^{*}=1$ and as $X_{i j t}$ increases, $\ln X_{i j t}^{*} \rightarrow \ln X_{i j t}$. This technique has been increasingly used 


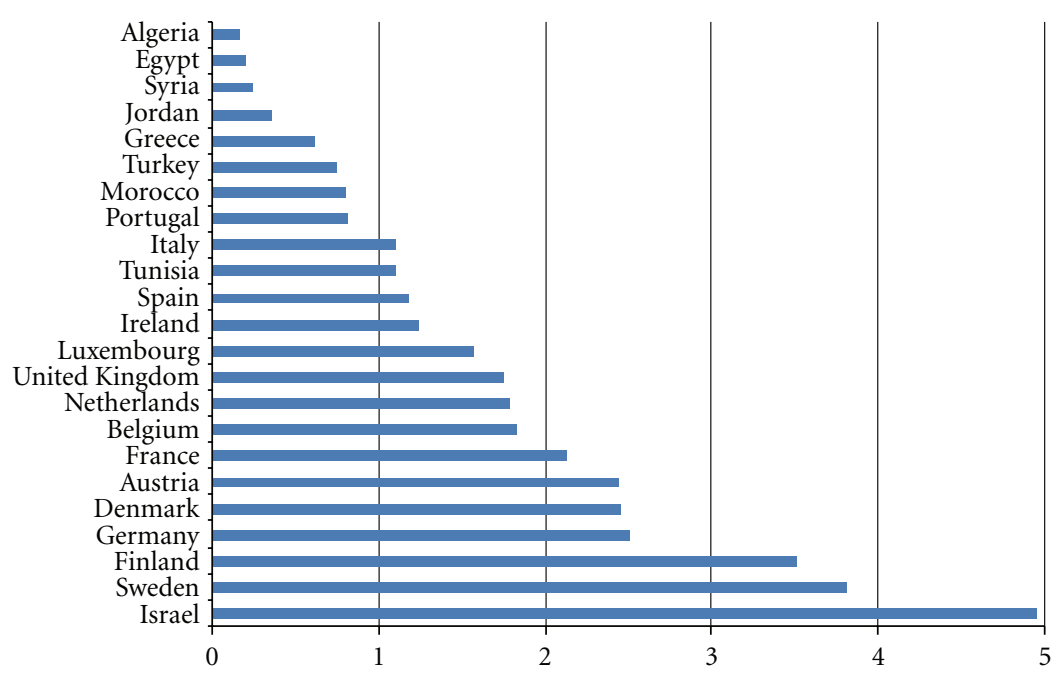

Figure 4: R\&D in the EuroMed area (as a \% of GDP, last year available) Source: UNCTAD [4].

in the recent literature, especially since Chen [23]. However, it does not specifically address the question of why some firms export while some others do not (selection bias). An alternative interesting method is the two-stage Heckman procedure (TSHP). It relies on the idea that zero trade flows in the dataset do not occur randomly but are the outcome of a selection procedure. As a result, the TSHP estimator provides a correction for this selection bias ${ }^{3}$.

The last bias is specific to the dynamic version of the model. It relates to the potential correlation between the error term and the lagged dependent variable. Due to the likely existence of simultaneity bias, the most appropriate method of estimation appears to be GMM. We used here the Arellano, Bond, and Bover's (ABB) Estimator [24, 25]. Basically, the initial structure of the model is similar to the HT models described in the Appendix (c).

To sum up, in order to address the econometric biases described above, the following estimators will be implemented: Hausman and Taylor, TSHP, as well as ABB for the dynamic model. The estimators are also controlled for crosssectional heteroskedasticity and serial correlation of the error term by using, respectively, the Huber-White Sandwich estimator and the AR1 Cocrane-Orcutt transformation. In addition, multicolinearity is controlled through the variance inflation factor (vif) statistics, which must be below 10 .

Finally, special attention has been paid to the fact that our model includes a great number of variables. The robustness of the results has been checked first by the use of a step by step estimation procedure. It makes it possible to estimate the model by adding (or removing) each variable one by one and checking whether the estimated parameters are sensitive to this addition (or deletion). Basically, the significance and the sign of the parameter estimates remain robust whatever the number of variables used in the model. As a second robustness test, the variance inflation factor (vif) has been calculated in order to control for multicolinearity. Results show that the vif statistics remains below 10, which is generally considered as the upper limit. This suggests that there is no significant multicolinearity bias due to the introduction of a great number of variables.

2.3. The Calculation of Trade Potentials. Once the estimation of the model is properly implemented, the calculation of export potentials (especially MPs export potential with regard to the EU) can be carried out from the estimation of the residuals of the model. The choice between the in-sample or out-of sample prediction depends on several factors. First, Egger [26] argues that the out-of-sample approach may avoid a misleading interpretation of the residuals. Second, if the countries considered have not fully achieved is their integration into the world economy (countries in transition), the out-of-sample prediction seems more appropriate, as it makes it possible to calculate what these countries' exports would be if they behaved like the countries which are fully integrated into the world economy. Given these considerations, we will use the out-sample methodology ${ }^{4}$.

One important issue is the choice between the static or dynamic specification regarding the calculation of trade potentials. Indeed, although the advantage of the dynamic equation is to account for past inertia in trade flows, one drawback is that it tends to even out both levels and variations of trade potential for a particular country, as well as differences in trade potential between countries. In the present study, the final results present the calculation of trade potential as the ratio between actual and fitted exports using the HT estimator (static), so as to provide greater differences across countries ${ }^{5}$.

This ratio indicates how much observed exports differ from fitted exports assuming that the countries considered behave like the other countries in the sample. Hence, if calculations show that the MPs' observed exports to the EU countries are below their potential level, this only means that the MPs exports to the EU are lower than they should be, once all the trade determinants have been considered. 
TABLE 1: Estimation results with alternative estimators.

\begin{tabular}{|c|c|c|c|c|c|c|}
\hline & \multirow{2}{*}{$\mathrm{HT}$} & \multirow{2}{*}{ TSHP } & \multirow{2}{*}{ Heterosc. (HW) } & \multirow{2}{*}{$\operatorname{AR}(1)$} & \multicolumn{2}{|c|}{ Dynamic ABB } \\
\hline & & & & & Short run & Long run \\
\hline GDP reporter & $0.8186^{* * *}$ & $0.7522^{* * *}$ & $0.8103^{* * *}$ & $0.8286^{* * *}$ & $0.1231^{* * *}$ & $0.8632^{* * *}$ \\
\hline GDP partner & $0.7719^{* * *}$ & $0.5594^{* * *}$ & $0.7706^{* * *}$ & $0.7829 * * *$ & $0.1101^{* * *}$ & $0.7721^{* * *}$ \\
\hline Tariffs & $-0.2624^{* * *}$ & $-0.1044^{* * *}$ & $-0.2529 * * *$ & $-0.1570^{* * *}$ & $-0.0186^{* * *}$ & $-0.1304^{* * *}$ \\
\hline Ntbs & $-0.0396^{* * *}$ & $-0.0227^{* *}$ & $-0.0382^{* * *}$ & $-0.0224^{* *}$ & $-0.0104^{* * *}$ & $-0.0529 * * *$ \\
\hline Logistics & $2.7629^{* * *}$ & $2.1222^{* * *}$ & $2.7718^{* * *}$ & $1.5238^{* *}$ & $0.2893^{* * *}$ & $2.029^{* * *}$ \\
\hline Common language & $0.3356^{* * *}$ & $0.3629 * * *$ & $0.3334^{* * *}$ & $0.5614^{* * *}$ & $0.0782^{* * *}$ & $0.5483^{* * *}$ \\
\hline Colony & $0.5165^{* * *}$ & $0.3255^{* *}$ & $0.5124^{* * *}$ & $0.6508^{* * *}$ & $0.0949 * * *$ & $0.6655^{* * *}$ \\
\hline Migration & $0.2744^{* * *}$ & $0.2130^{* * *}$ & $0.2705^{* * *}$ & $0.2712^{* * *}$ & $0.0327 * * *$ & $0.2293^{* * *}$ \\
\hline FDI stocks & $0.0274 * * *$ & $0.1702 * * *$ & $0.0254^{* * *}$ & $0.0189^{* * *}$ & $0.0007^{* *}$ & $0.0491 * * *$ \\
\hline Services & $0.1778^{* * *}$ & $0.1919^{* * *}$ & $0.1777^{* * *}$ & $0.4722^{* * *}$ & $0.0573^{* * *}$ & $0.4018^{* * *}$ \\
\hline Regional agreements & $1.7549^{* * *}$ & $1.3119^{* * *}$ & $1.7601^{* * *}$ & $2.0822 * * *$ & $0.3085^{* * *}$ & $2.1633^{* * *}$ \\
\hline Governance: rule of law & $0.2025^{* * *}$ & $0.1925^{* * *}$ & $0.2042^{* * *}$ & $0.1734^{* * *}$ & $0.0337 * * *$ & $0.2363^{* * *}$ \\
\hline Lagged exports & - & - & - & - & $0.8574^{* * *}$ & - \\
\hline Intercept & $-31.0560^{* * *}$ & $-22.9977 * * *$ & $-31.0025^{* * *}$ & $-32.9113^{* * *}$ & $-4.5888^{* * *}$ & $-32.1795^{* * *}$ \\
\hline Selection variable & - & $0.2577^{* * *}$ & - & - & - & - \\
\hline Adjusted $R$-squared & 0.7292 & - & - & - & - & - \\
\hline Vif & 2.47 & - & - & - & - & - \\
\hline Hausman & 24.8 & - & - & - & - & - \\
\hline
\end{tabular}

${ }^{* * *}$ Significant at $1 \%$ level; ${ }^{* *}$ significant at $5 \%$ level; *significant at $10 \%$ level.

\section{The Trade Potential between MPs and the EU: A Comparative Analysis of the Results}

This section starts presenting and discussing all econometric results for the model described previously. Then, the trade potential between MPs and the EU is calculated in comparison with that concerning other PTAs.

3.1. Estimation Results and Sensitivity Analysis. Table 1 shows the results with the estimators selected in the previous section. In this regard, it is worth mentioning that the parameter estimates are remarkably stable across these estimators, which is an indication of the robustness of the results. A second striking feature is that the parameter estimates are almost all significant at the 1\% level and all show the expected sign. For instance, the traditional gravity variables, such as GDP, common language, colony, and regional agreements are all positive. In addition, the trade costs variables are also all significant: tariffs and NTBs exhibit a negative sign whereas logistics performance shows a positive parameter estimate. These variables are more relevant than the traditional distance variable, which is too general as a measure of trade costs.

Factor movements are also greatly significant will a positive parameter estimates. This means that FDI and migration are complementary with trade. This is expected by the new trade theory which states that trade of goods cannot ensure FPE. It must be complemented by capital and human movements. This result is of particular importance since it shows that FDI and migration are both trade-creating. The same remark also applies to trade in services, which is complementary with trade of goods.
Governance, measured here first by the rule of law, is also positive and significant at the $1 \%$ level. This means that the quality of institutions and political factors do play a significant role in the creation of trade.

The lagged export variable is also significant, as expected. This suggests that exporting firms are more likely to export in the future than the other ones, due to sunk costs and hysteresis in international trade. Interestingly, the long run parameter estimates ${ }^{6}$ are very close to the static parameters (HT, TSHP, etc.).

Given that the parameter estimates are fairly stable across the selected estimators, the following analysis will focus on the HT estimator only, since it addresses the endogeneity problem, which is crucial in this type of analysis. Indeed, it uses instrumental variables for the variables which are endogenous, especially GDP, factor movement as well as services $^{7}$.

To go further in the analysis, Table 2 displays a sensitivity analysis which takes alternative proxies for regional agreement, trade costs, governance, and FDI. Starting with regional integration (HT1), the breakdown into the various preferential trading areas (PTAs) shows that they are all trade creating. However, the parameter estimate for the EuroMed agreement is of lower magnitude than those corresponding to the other parameters. This suggests that the Barcelona process has been less trade creating than the other regional agreements considered in this area. This result is not surprising since the regional integration process is not completed in the EuroMed area. In particular, during the period considered (2000-2009), MP countries did not complete their tariff removal with regard to the products originating from the EU. In addition, the persistence of NTBs, the 


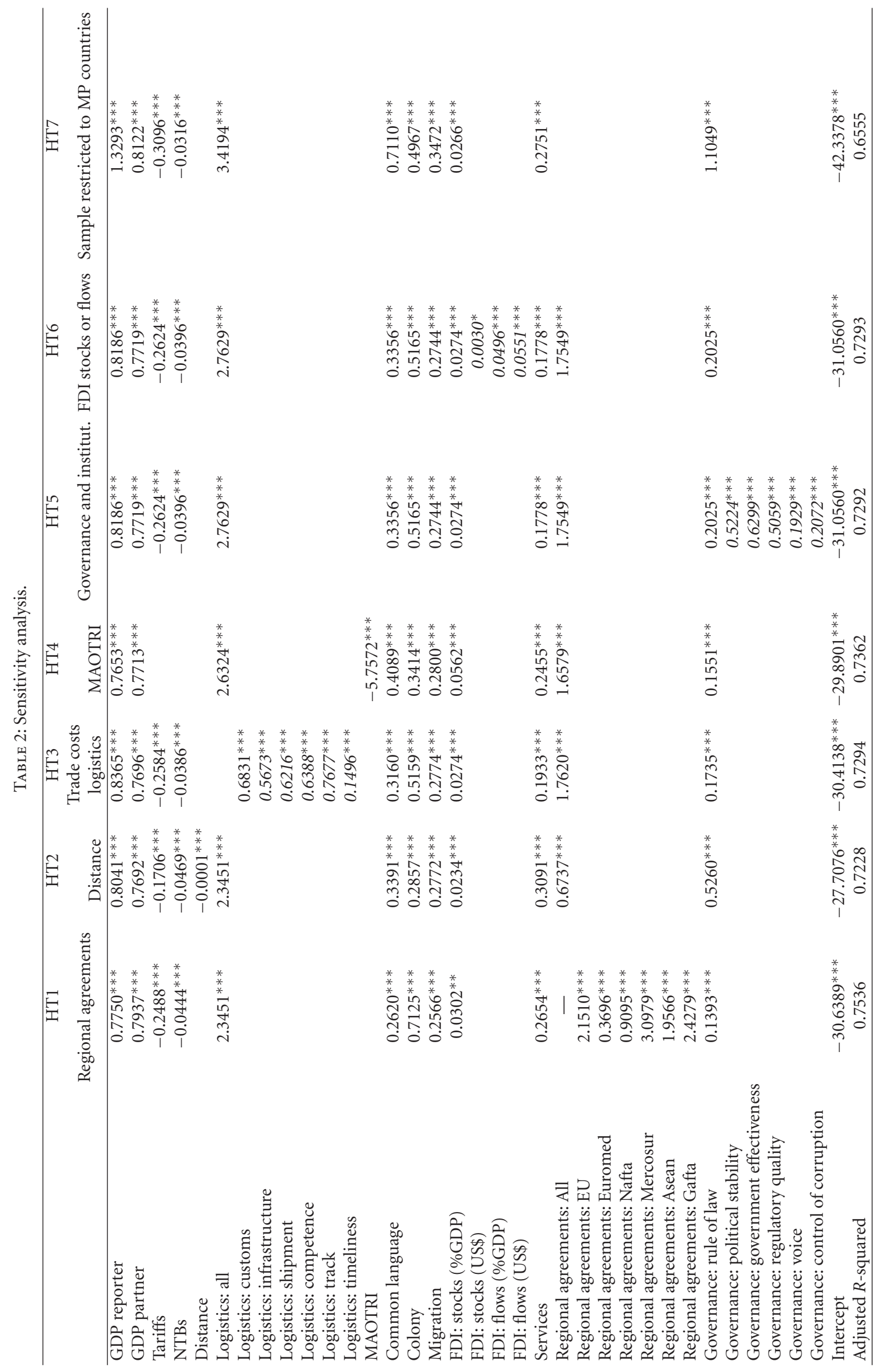


lack of market access into the EU for agricultural products originating from MP countries, the lack of integration in terms of services and FDI, and so forth... contribute to explain that the trade creation of the Barcelona agreement, although positive, is limited (see [1] for additional details). However, this does not mean that the trade potential between $\mathrm{MP}$ countries and the EU is more important than in the other areas, since it does not only depend on the effects of regional agreements but also on all the other trade determinants. This will be checked later on, when calculating trade potentials between the EU and MP countries.

Additional sensitivity analysis concerns trade costs. In this regard, HT2 uses the traditional distance variable, which is unsurprisingly negative and significant. HT4 takes the Market Access Overall Trade Restrictiveness Index (MAOTRI), which captures tariffs and NTBs faced by each exporter when selling to other countries [2]. This variable is negative and very significant. Finally, HT3 provides a breakdown of the logistics performance index into its various components, that is, customs efficiency, quality of infrastructures, efficiency in arranging international shipment, competence of the local logistics industry, ability to track shipments, as well as timeliness of shipment. All these components are very significant in explaining bilateral exports. They stress the key impact of the various logistics aspects in the trade creation process. This has important policy implications for MP countries which generally exhibit poor logistics efficiency compared with most other emerging or developed countries (refer to the Appendix for policy discussion).

In the same way, HT5 tests various governance indicators. It includes "voices" which measures to what extent citizens are able to participate in selecting their government, political stability (the absence of violence and terrorism), government effectiveness, regulatory quality, rule of law, as well as the control of corruption (for more details, refer to [5]). Interestingly, all these variables are significant and the $1 \%$ level. This means that the quality of the governance is a key factor in the trade creation process. Again, the poor quality of governance indicators in MP countries has major implication on trade. The corresponding policy implications will be further investigated later on.

The measurement of FDI, in terms of stocks or flows or in terms of value or as a percentage of GDP is tested in HT6. Parameter estimates are generally greatly significant whatever the proxy. The only exception is FDI stocks in US dollars, which are significant at $10 \%$ only.

The final sensitivity analysis consists in restricting the sample to the MP trade with the EU. This makes it possible to check whether there is any specificity in the MP-EU bilateral trade in comparison with the other country groups. In this regard, HT7 clearly shows that bilateral trade determinants are the same in the MP-EU relationship. In particular, trade costs significantly reduce trade (tariffs, NTBs, and bad logistics), factor movements are complementary to trade and governance is also strongly significant when explaining trade.

To sum up, the estimation results described in this section show that bilateral trade cannot only be explained by the traditional gravity equation which includes GDP, distance, language, and regional integration. Three sets of new variables are also of crucial importance, namely trade costs (including NTBs and logistics), factor movement (migration and FDI), as well as governance. Disregarding these variables when calculating trade potential may lead to a bias due to omitted variables. In this case, the residuals of the model would include the effects of these variables and trade potential could be overestimated. Conversely, by explicitly taking the new variables into account, it is expected that fitted exports better match observed exports. Thus, trade potential may not be as significant as in traditional studies.

3.2. The Calculation of Trade Potential. Table 3 exhibits the observed/fitted export ratio of MPs with regard to the EU. As stated previously, calculations have been implemented with the out-sample technique from the static HT estimator ${ }^{8}$. When this ratio is below one, this means that observed exports have not reached the level which is expected by the econometric model. Consequently, there is an export potential. Conversely, if the ratio is equal or greater than one, there is no more export potential available.

Overall, the export ratio is equal to 1 . Hence, MPs exports to the EU are on average exactly equal to the exports predicted by the model. This result slightly differs from that found in some existing studies which shows a small export potential $[6,7]$. The fact that the time period is most recent than in the other studies, cannot explain completely this difference. In fact, the main reason which explains this difference is the econometric specification which includes a larger number of variables, especially trade costs, factor movements and governance. In particular, the significant migration and FDI flows (or stocks) contribute to increase MPs exports to the EU. Disregarding these variable would lead to a bias related to omitted variables which in turn would increase the residuals in the model and thus show artificial export potential. In other words, migrations, FDI and services are significantly trade creating and thus contribute to explain why export potential is not significant. This explanation is supported by the fact that when reestimating the model as a standard gravity equation, that is, with distance only as a trade cost and without the variables related to FDI, migration and services, the export potential becomes significant. Indeed, the export ratio ranges between 0.8 and 0.9 depending on the estimator considered.

There are, however, slight differences across countries. For example, Table 3 shows that there is a small export potential concerning Mashrek countries, especially Lebanon and Syria. These countries are traditionally less trade oriented toward Europe. Conversely, there is no more potential for Maghreb countries and Turkey, which show a ratio greater than one, due to more trade openness and integration vis-àvis the EU.

From an import side, there is a small trade potential with Eastern and Northern EU countries whereas there is no more potential with the other EU countries (especially Southern countries).

In spite of these small geographical differences, the major feature of Table 3 is that MPs' export potential with the EU 
TABLE 3: The export potential of MPs with regard to the EU (observed/fitted exports ratio).

\begin{tabular}{|c|c|c|c|c|c|c|c|c|c|c|}
\hline Impoter $\backslash$ exporters & Algeria & Egypt & Israel & Jordan & Lebanon & Morocco & Syria & Tunisia & Turkey & MP average \\
\hline Austria & 0,744 & 0,852 & 0,997 & 1,000 & 0,808 & 1,072 & 1,111 & 1,004 & 1,000 & 0,954 \\
\hline Belgium & 1,172 & 1,088 & 1,184 & 1,068 & 1,023 & 1,090 & 1,060 & 1,417 & 1,035 & 1,093 \\
\hline Cyprus & 1,146 & 1,157 & 1,296 & 1,098 & 1,150 & 0,993 & 1,084 & 1,150 & 1,149 & 1,136 \\
\hline Czech Rep. & 0,665 & 0,971 & 1,084 & 0,899 & 0,893 & 1,031 & 1,012 & 0,971 & 1,090 & 0,957 \\
\hline Denmark & 0,974 & 0,930 & 1,047 & 0,938 & 0,868 & 0,907 & 0,813 & 0,992 & 1,034 & 0,945 \\
\hline Finland & 0,999 & 0,967 & 1,064 & 0,950 & 0,810 & 0,991 & 0,789 & 0,838 & 1,017 & 0,936 \\
\hline France & 1,061 & 1,007 & 1,033 & 0,908 & 0,893 & 1,049 & 1,061 & 1,084 & 1,011 & 1,012 \\
\hline Germany & 0,998 & 0,970 & 1,033 & 0,891 & 0,875 & 1,011 & 1,097 & 1,081 & 1,004 & 0,995 \\
\hline Greece & 1,165 & 1,058 & 1,074 & 0,937 & 1,022 & 1,107 & 1,072 & 1,056 & 1,058 & 1,061 \\
\hline Hungary & 0,683 & 0,933 & 1,068 & 1,069 & 0,766 & 0,945 & 0,882 & 0,979 & 1,076 & 0,933 \\
\hline Ireland & 0,736 & 0,972 & 1,023 & 0,899 & 0,885 & 1,052 & 0,680 & 1,019 & 1,067 & 0,926 \\
\hline Italy & 1,205 & 1,060 & 1,067 & 1,019 & 0,939 & 1,042 & 1,137 & 1,144 & 1,059 & 1,075 \\
\hline Lithuania & 1,009 & 1,021 & 1,100 & 0,927 & 0,796 & 0,999 & 0,761 & 0,874 & 1,121 & 0,956 \\
\hline Luxembourg & 1,046 & 0,792 & 1,052 & 0,792 & 0,760 & 1,035 & 1,013 & 1,036 & 1,021 & 0,950 \\
\hline Netherlands & 1,250 & 1,103 & 1,118 & 1,102 & 0,932 & 1,066 & 1,084 & 1,125 & 1,011 & 1,090 \\
\hline Poland & 1,080 & 0,943 & 1,056 & 1,031 & 0,832 & 1,104 & 0,938 & 1,084 & 1,014 & 1,016 \\
\hline Portugal & 0,770 & 0,968 & 1,050 & 0,978 & 0,832 & 1,124 & 1,033 & 1,058 & 1,077 & 0,988 \\
\hline Romania & 1,298 & 0,983 & 1,037 & 1,032 & 0,966 & 1,056 & 0,895 & 1,027 & 1,136 & 1,048 \\
\hline Slovakia & 0,899 & 0,999 & 0,990 & 1,052 & 0,687 & 1,156 & 0,669 & 1,126 & 1,077 & 0,962 \\
\hline Spain & 1,202 & 1,091 & 1,080 & 1,027 & 0,972 & 1,112 & 1,110 & 1,153 & 1,023 & 1,086 \\
\hline Sweden & 1,102 & 0,918 & 1,033 & 0,875 & 0,910 & 0,956 & 0,812 & 1,038 & 1,014 & 0,962 \\
\hline Switzerland & 1,041 & 0,927 & 1,142 & 1,150 & 1,116 & 1,099 & 0,776 & 1,146 & 1,070 & 1,052 \\
\hline United Kingdom & 1,114 & 0,983 & 0,997 & 0,934 & 0,935 & 1,073 & 1,026 & 1,112 & 1,036 & 1,023 \\
\hline EU average & 1,016 & 0,987 & 1,071 & 0,982 & 0,899 & 1,047 & 0,955 & 1,053 & 1,052 & 1,007 \\
\hline
\end{tabular}

TABle 4: The export potential in the NAFTA (observed/fitted exports).

\begin{tabular}{lcccc}
\hline Importer $\backslash$ exporter & Mexico & USA & Canada & NAFTA aver. \\
\hline Mexico & & 0,996 & 0,994 & 0,995 \\
USA & 0,997 & & 1,005 & 1,001 \\
Canada & 1,026 & 0,999 & & 1,013 \\
\hline NAFTA average & 1,011 & 0,998 & 1,000 & 1,003 \\
\hline
\end{tabular}

is insignificant. This result has important policy implications which will be discussed in the next section.

Tables 4, 5, and 6 provide and interesting comparison with other geographical areas. Interestingly, the conclusion is identical to the previous one, that is, there is no further export potential within the other PTAs, namely NAFTA, MERCOSUR, and ASEAN, despite small potentials for selected bilateral flows. This means that MP countries exports toward the EU are not different from those on the other PTAs. In other words, there is no specificity of trade relationships between MPs and the EU relative to the other PTAs.

\section{Conclusion and Policy Implications}

The main result of this study is that MPs have reached their export potential with the EU. In other words, the current export level from MPs to the EU is just equal to the level predicted by the model. It has also been shown that there is no specificity of the MP-EU trade potential in comparison with the other main PTAs (NAFTA, MERCOSUR, and ASEAN) which have also reached their trade potential.

The policy implications of the results are the following. First, the fact that Mediterranean countries have reached their export potential just means that their exports to the $\mathrm{EU}$ are at a "normal" level compared to the other trading areas in the world. However, this does not mean that exports cannot increase in the coming years. This can be achieved by the following tools which can be implemented to increase MPs export performance. The first consists in progressing in reducing trade costs, especially NTBs. As observed above, the NTBs calculated in terms of AVEs are much higher in Mediterranean countries than in the EU. In addition, the econometric model presented previously clearly showed that the presence of NTBs is trade-reducing. Consequently, it seems that MENA country could significantly increase their trade by reducing NTBs. This is not to say that NTBs must be completely removed, since some of them may be useful for the protection of specific consumers or industries. However, a downward move toward world average would help creating trade.

As a second tool, Mediterranean countries should improve their logistics performance toward EU standards. Indeed, Mediterranean countries show a poor logistics performance compared to the EU. In this regard, our results suggest that $1 \%$ increase in the LPI leads to a $2.76 \%$ rise in 
TABLE 5: The export potential in the MERCOSUR (observed/fitted exports).

\begin{tabular}{|c|c|c|c|c|c|c|}
\hline Importer $\backslash$ exporter & Argentina & Brazil & Chile & Paraguay & Uruguay & MERCOSUR \\
\hline Argentina & & 0,998 & 0,922 & 1,022 & 0,991 & 0,983 \\
\hline Brazil & 1,002 & & 0,980 & 1,010 & 1,009 & 1,000 \\
\hline Chile & 0,986 & 0,964 & & 1,071 & 0,980 & 1,000 \\
\hline Paraguay & 1,019 & 1,003 & 0,970 & & 1,083 & 1,019 \\
\hline Uruguay & 0,988 & 0,977 & 0,963 & 1,236 & & 1,041 \\
\hline MERCOSUR average & 0,999 & 0,985 & 0,959 & 1,085 & 1,016 & 1,009 \\
\hline
\end{tabular}

TABLE 6: The export potential in the ASEAN (observed/fitted exports).

ASEAN

Importer $\backslash$ exporter Cambodia China India Indonesia Japan Malaysia Philippines Rep. of Korea Singapore Thailand Vietnam aver.

\begin{tabular}{|c|c|c|c|c|c|c|c|c|c|c|c|c|}
\hline Cambodia & & 0,993 & 0,901 & 1,074 & 0,924 & 1,081 & 0,940 & 1,017 & 1,130 & 1,104 & 1,096 & 1,026 \\
\hline China & 0,849 & & 0,897 & 0,982 & 0,963 & 0,974 & 0,985 & 1,005 & 0,984 & 0,990 & 1,002 & 0,963 \\
\hline India & 0,827 & 0,947 & & 0,998 & 0,888 & 1,006 & 0,839 & 0,945 & 0,979 & 0,959 & 0,924 & 0,931 \\
\hline Indonesia & 0,837 & 0,916 & 0,885 & & 0,917 & 1,013 & 0,937 & 0,953 & 1,079 & 0,990 & 0,970 & 0,950 \\
\hline Japan & 0,914 & 0,951 & 0,870 & 1,036 & & 1,031 & 1,017 & 0,936 & 1,009 & 1,016 & 1,045 & 0,983 \\
\hline Malaysia & 0,974 & 0,965 & 0,958 & 1,091 & 0,995 & & 1,078 & 1,013 & 1,129 & 1,105 & 1,107 & 1,042 \\
\hline Philippines & 0,886 & 0,961 & 0,878 & 1,054 & 0,989 & 1,079 & & 1,022 & 1,066 & 1,073 & 1,122 & 1,013 \\
\hline Rep. of Korea & 0,922 & 0,952 & 0,879 & 0,998 & 0,922 & 0,997 & 1,001 & & 1,006 & 0,952 & 0,984 & 0,962 \\
\hline Singapore & 1,082 & 0,942 & 0,939 & 1,085 & 0,984 & 1,088 & 1,010 & 1,024 & & 1,067 & 1,080 & 1,030 \\
\hline Thailand & 0,956 & 0,947 & 0,934 & 1,056 & 1,014 & 1,110 & 1,057 & 1,006 & 1,113 & & 1,075 & 1,027 \\
\hline Vietnam & 0,966 & 0,955 & 0,922 & 1,055 & 0,965 & 1,049 & 0,988 & 1,023 & 1,053 & 1,012 & & 0,999 \\
\hline ASEAN average & 0,921 & 0,953 & 0,906 & 1,043 & 0,956 & 1,043 & 0,985 & 0,994 & 1,055 & 1,027 & 1,041 & 0,993 \\
\hline
\end{tabular}

exports. As a result, there is a considerable margin for trade increase by improving logistics performance.

Improving governance should also be a priority for Mediterranean countries. Indeed, we have shown that Mediterranean countries are well below the EU average in this regard. Our results clearly showed that an increase in any governance indicator leads to a significant trade increase.

One original aspect of the present study is the inclusion of factor movements as trade determinants. As explained previously, considering a world in imperfect competition leads to the complementarity between trade and factor movement, as trade itself cannot equalize factor prices. The present study validates this theoretical assumption by clearly accepting the complementarity relationship between trade and migration. For example, it has been shown that $1 \%$ outward migration stock leads to an increase in exports by about $0.2 \%$. This means that MENA countries, which have exported people to the EU have consequently created exports. As a result, migration can be viewed as a tool to create exports from MPs to the EU. This result is not new in the literature but it is clearly highlighted in the present study for the EU-MP relationships ${ }^{9}$.

In the same way, our model showed that $1 \%$ increase in FDI outward stocks (as a percentage of GDP) leads to $0.03 \%$ increase in exports. As a result, FDI can be seen as a tool for EU countries to create exports to MENA countries. In other words, it seems that the trade-migration-FDI relationship is self-reinforcing. This means that if the EU and MENA countries have a common objective which is to develop trade relationships, then appropriate migration and FDI policies can contribute to achieve this objective.

In sum, the remarks developed above show that trade policy (regional integration based on tariffs and NTB policy) can no longer be seen as the only tools designed at developing trade relationships between two areas. Indeed, as shown previously, trade can be developed by many other tools or policies involving especially logistics performance, FDI, migration, and governance.

Finally, the EU and MP countries can also rethink their partnership toward new tools that can also create trade, job and growth in the future, that is, education, research, and environment. Education and research is the first major challenge. Indeed, this makes it possible to upgrade the average skill levels in an economy, which in turn can boost the innovation process. In this regard, there is an increasing literature which shows the link between education-researchinnovation on the one hand and trade-growth-employment on the other [27-29]. In spite of real efforts recently undertaken in some MENA countries, the gap is still large with emerging or developed countries, especially the EU in terms of education and research, as shown previously.

As a final point, environment is about to become a central issue not only at worldwide level, but also for MENA countries specifically. For example, the problems of wastes (treatment and recycling), de-pollution (grounds, air, and sea), as well as the development of clean energies (solar, wind, 
etc.) are becoming critical issues for sustainable development in MENA countries. In this regard, there is a huge work to be made in this area. From an economic point of view, dealing with environmental aspects can directly create a lot of jobs, while creating trade and growth in MENA countries. This win-win approach (in terms of environment and economics) is a central policy issue which must be dealt with by policymakers very soon.

\section{Appendix}

\section{A. Technical Annex}

(a) The Theory behind New Gravity Models: The Anderson and van Wincoop [10] Approach. In recent years, the most popular specification of the gravity model can be found in Anderson and van Wincoop [10]. These authors develop a consistent general theoretical framework with special emphasis on trade costs from which the following gravity equation can be derived.

$$
X_{i j t}=\left(\frac{Y_{i t}^{\alpha} Y_{j t}^{\gamma}}{Y_{w t}^{\mu}}\right)\left(\frac{T_{i j t}}{P_{i t} P_{j t}}\right)^{1-\sigma}
$$

$X_{i j t}$ corresponds to country $i$ 's exports to country $j$ at year $t$. The first term in brackets includes the mass variables, namely, country i's GDP $\left(Y_{i t}\right)$, country j's GDP $\left(Y_{j t}\right)$, as well as world GDP $\left(Y_{w t}\right)$. The second term in brackets reflects trade costs. They include the bilateral trade cost $\left(T_{i j t}\right)$ as well as implicit prices $\left(P_{i t}\right.$ and $\left.P_{j t}\right)$ which measure multilateral trade costs [10].

In the same way, implicit prices can be written as follows ${ }^{10}$ :

$$
\begin{array}{ll}
P_{j t}^{(1-\sigma)} & =\sum_{i} P_{i t}^{\sigma-1} \theta_{i t} t_{i j t}^{1-\sigma}, \quad \forall j \\
P_{i t}^{(1-\sigma)} & =\sum_{j} P_{j t}^{\sigma-1} \theta_{j t} t_{i j t}^{1-\sigma}, \quad \forall i,
\end{array}
$$

with $\theta_{i}$ and $\theta_{j}$ denoting country $i$ and $j$ 's income shares.

Since prices depend on the trade barriers applied to all countries, they reflect multilateral trade resistance, that is, the trade barriers that an exporter faces with all importing countries, not only its bilateral partner $j$. As a result, a rise in the trade costs vis-à-vis all its partners leads country $i$ to trade more with its bilateral partner $j$.

The log-linearization of equation (A.1) leads to the new gravity equation where exports depend on GDP, distance as well as bilateral and multilateral trade costs.

(b) The Calculation of Ad-Valorem Equivalents for NTBs: The Kee et al. [2] Approach. The Kee et al. [2] approach, also referred to by [2] makes it possible to calculate ad-valorem equivalents of NTBs. Two stages must be implemented. The first includes an estimation of the quantity impact of NTMs on imports. In a second stage, this impact is transformed into price effects, using import demand elasticities calculated in [2].
In the first stage, the basic equation to be estimated is the following:

$$
\begin{aligned}
& \log \left(m_{n, c}\right) \\
& \quad=\alpha_{n}+\sum_{k} \alpha_{n, k} C_{c}^{k}+\beta_{n, c}^{n t b} \mathrm{ntm}_{n, c}+\varepsilon_{n, c} \log \left(1+t_{n, c}\right)+\mu_{n, c}
\end{aligned}
$$

where $m_{n, c}$ is the import value of good (or industry) $n$ in country $c$ from $i, C_{c}^{k}$ denotes a vector of country characteristics variables in country $c$. They include relative factor endowment and the sum of GDP (of the reporter and the partner country) which captures economic size. The geographic distance between MED countries and their Mediterranean partners is also included. $\mathrm{ntm}_{n, c}$ is a dummy variable which reflects the existence of bilateral NTMs. $t_{n, c}$ is the bilateral tariff on good $n$ in country $c$ and $\varepsilon_{n, c}$ corresponds to the import demand elasticity.

The initial model is subsequently modified as follows. First, import-demand elasticities estimated in [2] are substituted into (A.3). Second, the tariff term is moved to the left-hand side to address the endogeneity of tariffs. This introduces a new error term $k_{n, c}$. Third, a White correction is introduced in order to tackle heteroscedasticity of the error term. Fourth, product specific effects are also introduced so as to capture the variation of $\beta$ s across tariff lines. Fifth, appropriate instrumental variables are included to address the endogeneity problem related to NTMs. Indeed, as shown in Lee and Swagel [30], such endogeneity may lead to a downward bias on the estimated impact of NTMs on imports, which would result in underestimating AVEs. Sixth, a two-step estimation procedure is implemented to estimate the $\beta$ coefficients, following a Heckman two-stage procedure.

After these transformations, the final estimated equation becomes the following

$$
\begin{aligned}
& \log \left(m_{n, c}\right)-\varepsilon_{n, c} \log \left(1+t_{n, c}\right) \\
& \quad=\alpha_{n}+\sum_{k} \alpha_{n, k} C_{c}^{k}+\left(-e^{\beta_{n, c}^{n t b}+\sum_{k} \beta_{n, c}^{n t b} C_{c}^{k}}\right) \mathrm{ntm}_{n, c}+\kappa_{n, c} .
\end{aligned}
$$

Estimating (A.4) with the two-step Heckman procedure (TSHP) described later. The last step consists of calculating the AVEs after transformation of the quantity impact derived from (A.4) into price-equivalents. This leads to the following

$$
\mathrm{AVE}=\frac{\partial \log P^{d}}{\partial \mathrm{NTM}},
$$

where $P_{d}$ denotes the domestic price. This equation defines AVEs as the effects of NTMs on prices. The introduction of the price variable is necessary since, like ad-valorem tariffs, NTM effects must be calculated on prices and not on quantities. After differentiation of (A.3), it is easy to obtain:

$$
\operatorname{AVE}_{n, c}^{n t b}=\frac{e^{\beta_{n, c}^{n t b}}-1}{\varepsilon_{n, c}}
$$


(c) The Hausman and Taylor Estimato (HT)r. Egger [20] suggests using the Hausman and Taylor [31] specification, especially for the calculation of trade potential.

This model has been computed following Greene [32] procedure, where basically, all variables $(Z)$ in (A.1) are transformed as follows:

$$
\begin{gathered}
Z_{i j t}^{*}=Z_{i j t}-\theta_{i j} Z_{i j t}^{m}, \\
\theta_{i j}=1-\frac{\sigma_{v}}{\sigma_{s}}, \\
\sigma_{s}=\left(T_{i j} \sigma_{u}^{2}+\sigma_{v}^{2}\right)^{0.5},
\end{gathered}
$$

where $Z_{i j t}^{*}$ denotes any variables in (A.1), $Z_{i j t}^{m}$ reflects the group means of these variables and $T_{i j}$ is the number of bilateral observations; $\sigma_{v}^{2}$ and $\sigma_{\mu}^{2}$ corresponds to the Within and between variance respectively.

This model can be computed as follows: deviations from group means are firstly used in order to consistently estimate the parameters of the time-varying independent variables. This has been carried out through LSDV, which provides a consistent estimator of $\sigma_{v}$. As a second step, we used group means residuals as the dependent variable, regressed on the time-invariant variables, to provide a consistent estimator of the parameters of the latter. This can be implemented through 2SLS. As instruments, we selected the variables which are assumed to be uncorrelated with the bilateral residuals. The residual variance estimator is a consistent estimator of $\sigma_{s}$.

As a next step, the estimation of $\sigma_{s}$ and $\sigma_{v}$ leads us to deduce an estimator of $\sigma_{\mu}^{2}$. This makes it possible to calculate the Hausman and Taylor estimators, through Weighted IV regression applied to the whole model with the transformed variables. In order to overcome the endogeneity bias, a feasible set of instruments can be used, namely, the deviation from group means of the time-varying variables, the time-invariant uncorrelated variables, as well as the timevarying uncorrelated variables group means (see detailed computation procedure in [32, p.E8-27] or [20, p.185]). The model is only identified if the number of uncorrelated time-varying variables is at least as large as the number of correlated time-invariant variables.

\section{Acknowledgments}

This paper has been written with financial assistance from the Commission of the European Communities, through the FEMISE network (contribution to the FEMISE annual report 2011). The views expressed herein are those of the authors and therefore in no way reflect the official opinion of the European Commission. The author is very grateful to Frederic Blanc and Constantin Tsakas (FEMISE) for their research assistance concerning the development of the database.

\section{Endnotes}

1. The first Association Agreements were signed in the 60s with Turkey, Morocco, and Tunisia. They granted tariff preferences to imports originating from these countries toward the EC. These agreements have been progressively extended to all MPs, i.e., Maghreb and Mashrek countries and the Barcelona process paved the way for the implementation of a free trade area (FTA) between the EU and its MPs.

2. Basically, the first stage estimates a pure fixed effects model to obtain an estimate of the unit effects. The second step implements an instrumental regression of the fixed effects vector on the time invariant variables. This makes it possible to decompose the fixed effects vector into a first component explained by the timeinvariant variables and a second component, namely the unexplainable part (the error term). It also addresses the endogeneity problem. In the last stage, the model is reestimated by pooled OLS, including all explanatory variables, the time-invariant variables and the error term. This third step ensures the control for colinearity between time-varying and invariant right hand side variables.

3. It can be estimated is several stages. The first stage estimates a Probit model (test for the probability of country $i$ to exports to country $j$ ). In a second stage, provided that exports occur, the effects of trade barriers and other variables can be estimated though the choice of an appropriate estimator [14]. This method seems particularly interesting in the present research study because it specifically takes into account the information contained in the zero or missing data. The main problem is to choose the appropriate selection variable. Recent research at firm level (Melitz [33]) suggests that in case of different productivity levels between firms, the existence of fixed costs produces a selection of the firms. As a result, only the most productive ones succeed in exporting whereas the others remain on the domestic market. This suggests that productivity at firm level can be used as the selection variable in this kind of model. Unfortunately, in the present paper, data are not available for all countries at firm level so that this selection variable cannot be implemented. Instead, the lagged export variable will also be used as the selection variable. As already explained in Section 3, this can be justified by considering hysteresis in international trade [19].

4. As a sensitivity analysis, the in-sample method has also been carried out and it proved to provide very close results.

5. In fact, there appears to be a lack of a rigorous testing framework that encompasses the dynamic GMM estimator and its static counterpart, as it is generally recognized [34].

6. The long run parameter estimates are calculated by the ratio between the short run parameter on the one hand and ( 1 -the lagged exports parameter estimate) on the other.

7. The other biases seem less important: indeed, there is only $1.2 \%$ of zero-observations. This strongly reduces 
the corresponding bias even if the TSHP shows a positive parameter related to the selection variable. In the same way, the bias due to heteroskedasticity and autocorrelation seems to be limited since the corresponding parameter estimates are close to the HT estimates.

8. As a sensitivity analysis, calculations have also been carried out with the in-sample technique and with the dynamic $\mathrm{ABB}$ estimator. Results are remarkably stable whatever the technique and estimator. This is why only the static out-sample approach is presented here.

9. Concerning the trade-migration relationship, refer for instance to Co et al., [35], Iranzo and peri [36] as well as Brian et al [37].

10. See Anderson and van Wincoop [10] for the complete derivation of the model.

\section{References}

[1] N. Péridy, "Evaluation de l'impact du partenariat euroméditerranéen 15 ans après Barcelone : quels enseignements ? Quelles actions?" in Rapport du FEMISE sur le Partenariat Euro-méditerranéen: Le Partenariat Méditerranéen à la croisée des chemins, A. Gallal and J. L. Reiffers, Eds., pp. 3-20, 2010.

[2] H. L. Kee, A. Nicita, and M. Olarreaga, "Estimating trade restrictiveness indices," Economic Journal, vol. 119, no. 534, pp. 172-199, 2009.

[3] World Bank, "Connecting to compete: trade logistics in the global economy," International Bank for Reconstruction and Development, The World Bank, 2011.

[4] UNCTAD, World Development Indicators, 2009, 2010.

[5] D. Kaufmann, A. Kraay, and M. Mastruzzi, "The worldwide governance indicators: methodology and analytical issues," Draft Policy Research Working Paper, The World Bank, 2010.

[6] N. Péridy, "La nouvelle politique de voisinage de l'Union Européenne: Une estimation des Potentiels de Commerce," Revue Economique, vol. 57, no. 4, pp. 727-746, 2006.

[7] Y. F. L. Lee and A. Gohar, "Trade and intra-regional integration: is Arab region a potential candidate for economic union?" Journal of Economic Cooperation and Development, vol. 31, no. 3, pp. 67-82, 2010.

[8] H. Boughanmi, "The trade potential of the Arab gulf cooperation Countries (GCC): a gravity model approach," Journal of Economic Integration, vol. 23, no. 1, pp. 42-56, 2008.

[9] J. Abedini and N. Péridy, "The greater arab free trade area (GAFTA): an estimation of trade effects (with Javad Abedini)," Journal of Economic Integration, vol. 23, no. 4, pp. 848-872, 2008.

[10] J. E. Anderson and E. van Wincoop, "Gravity with gravitas: a solution to the border puzzle," American Economic Review, vol. 93, no. 1, pp. 170-192, 2003.

[11] J. R. Markusen, "Factor movements and commodity trade as complements," Journal of International Economics, vol. 14, no. 3-4, pp. 341-356, 1983.

[12] A. Venables, "Trade liberalization and factor mobility: an overview," in Migration: The Controversies and the Evidence, R. Faini, J. de Melo, and K. Zimmermann, Eds., Cambridge University Press, CEPR, 1999.

[13] B. H. Baltagi and P. X. Wu, "Unequally spaced panel dataregressions with $\mathrm{AR}(1)$ disturbances," Econometric Theory, vol. 15 , no. 6, pp. 814-823, 1999.
[14] W. Greene et al., Econometric Analysis, Prentice-Hall International, New York, NY, USA, 6th edition, 2006.

[15] E. Helpman, P. R. Krugman et al., Market Structure and Foreign Trade: Increasing Returns, Imperfect Competition and the International Economy, MIT Press, Cambridge, Mass, USA, 1985.

[16] J. R. Markusen and R. M. Wigle, "Explaining the volume of North-South trade," Economic Journal, vol. 100, no. 403, pp. 1206-1215, 1990.

[17] S. J. Evenett and W. Keller, "On theories explaning the success of the gravity equation," Journal of Political Economy, vol. 110, no. 2, pp. 281-316, 2002.

[18] R. C. Feenstra, J. R. Markusen, and A. K. Rose, "Using the gravity equation to differentiate among alternative theories of trade," Canadian Journal of Economics, vol. 34, no. 2, pp. 430447, 2001.

[19] R. Baldwin, P. Krugman et al., "Persistent trade effects of exchange rate shocks," Quarterly Journal of Economics, vol. 104, no. 4, pp. 635-654, 1989.

[20] P. Egger, "On the problem of endogenous unobserved effects in the estimation of gravity models," Journal of Economic Integration, vol. 19, no. 1, pp. 182-191, 2004.

[21] T. Plümper and V. E. Troeger, "Efficient estimation of timeinvariant and rarely changing variables in finite sample panel analyses with unit fixed effects," Political Analysis, vol. 15, no. 2, pp. 124-139, 2007.

[22] W. Greene, "Fixed Effects Vector Decomposition: A Magical Solution to the Problem of Time Invariant Variables in Fixed Effects Models," Mimeo, 2010, http://pages.stern.nyu.edu/ wgreene.

[23] N. Chen, "Intra-national versus international trade in the European Union: why do national borders matter?" Journal of International Economics, vol. 63, no. 1, pp. 93-118, 2004.

[24] M. Arellano and S. Bond, Dynamic Panel Data Estimation Using DPD98 for Gauss: A Guide for Users, CEMFI, Madrid, Spain, 1998.

[25] M. Arellano and O. Bover, "Another look at the instrumental variable estimation of error-components models," Journal of Econometrics, vol. 68, no. 1, pp. 29-51, 1995.

[26] P. Egger, "An econometric view on the estimation of gravity models and the calculation of trade potentials," World Economy, vol. 25, no. 2, pp. 297-312, 2002.

[27] B. Amable, "International specialisation and growth," Structural Change and Economic Dynamics, vol. 11, no. 4, pp. 413$431,2000$.

[28] B. Milanovic, "Economic integration and income convergence: not such a strong link?" Review of Economics and Statistics, vol. 88, no. 4, pp. 659-670, 2006.

[29] N. Péridy, "Innovation, growth and convergence in the Euro-Mediterranean area: implications for MENA countries," Economics Bulletin, vol. 30, no. 4, pp. 2978-2986, 2010.

[30] J. W. Lee and P. Swagel, "Trade barriers and trade flows across countries and industries," Review of Economics and Statistics, vol. 79, no. 3, pp. 372-382, 1997.

[31] J. Hausman and W. Taylor, "Panel data and unobservable individual effects," Econometrica, vol. 49, no. 6, pp. 1377-1398, 1981.

[32] W. Greene, Econometric Modeling Guide, Econometric Software edition, 2004.

[33] M. Melitz, "The impact of trade on intra-industry reallocation and aggregate industry productivity," Econometrica, vol. 71, no. 6, pp. 1695-1725, 2003.

[34] M. Harris and L. Matyas, "Modelling export flows in the APEC region: static and dynamic gravity model approaches," Asia 
Pacific Journal of Economics and Business, vol. 5, no. 1, pp. 97118, 2001.

[35] C. Y. Co, P. Euzent, and T. Martin, "The export effect of immigration into the USA," Applied Economics, vol. 36, no. 6, pp. 573-583, 2004.

[36] S. Iranzo and G. Peri, "Migration and trade: theory with an application to the Eastern-Western European integration," Journal of International Economics, vol. 79, no. 1, pp. 1-19, 2009.

[37] A. Brian, P. P. Combes, and M. Lafourcade, "Product complexity, quality of institutions and the pro-trade effect of immigrants," CEPR Discussion Paper 7192, 2009. 


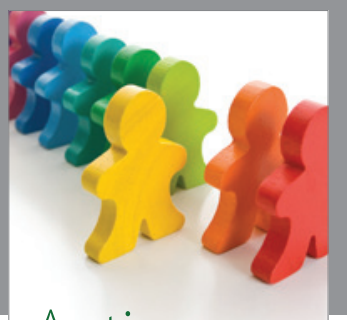

Autism

Research and Treatment
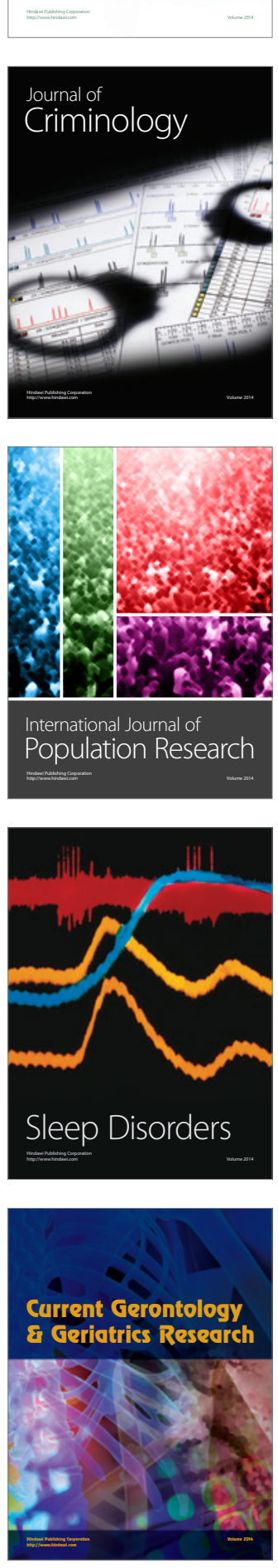
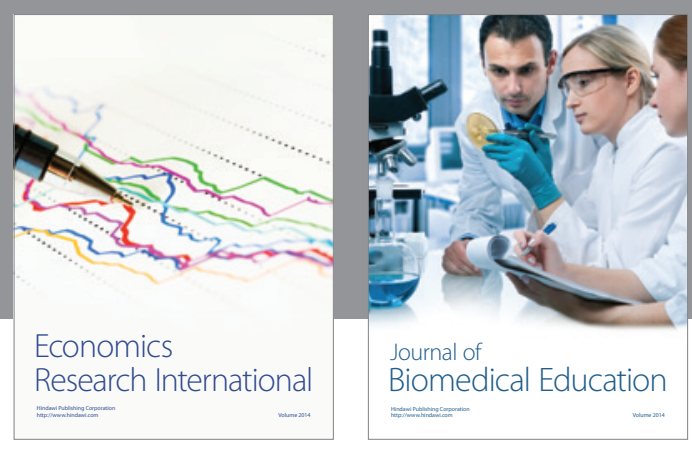

Journal of

Biomedical Education

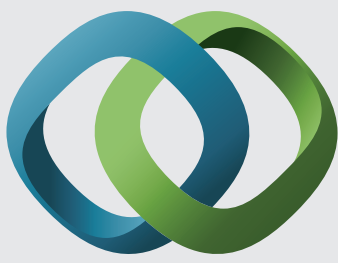

\section{Hindawi}

Submit your manuscripts at

http://www.hindawi.com
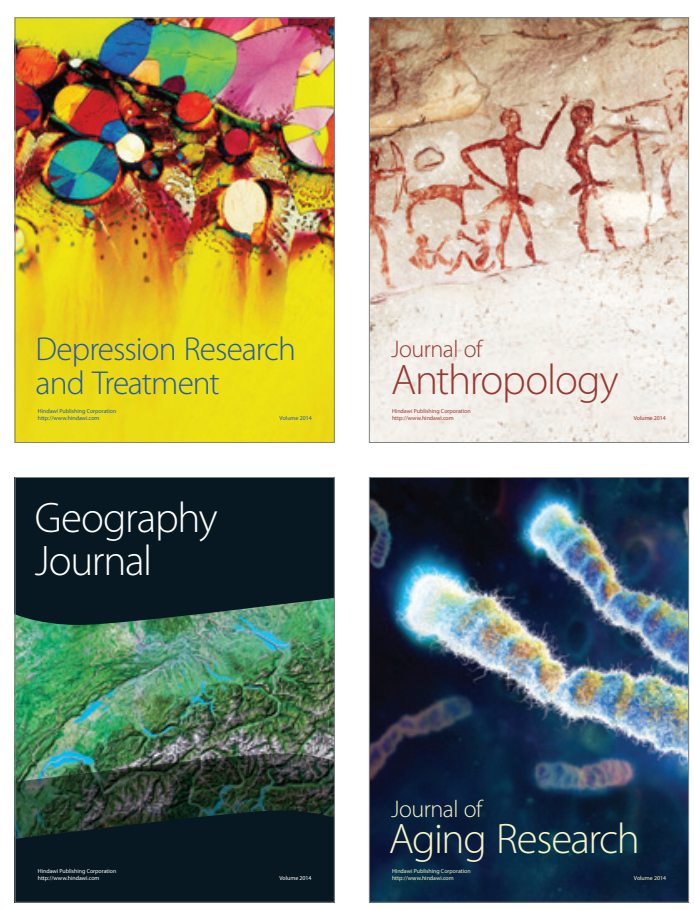

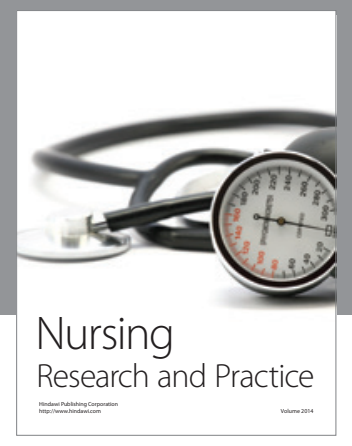

Nursing

Research and Practice

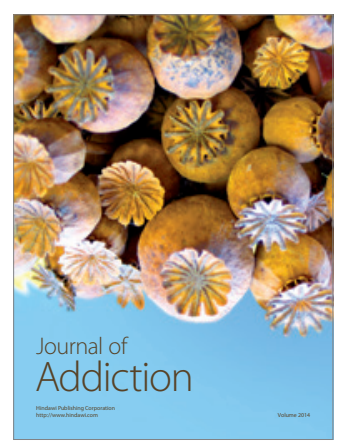

Child Development

Research

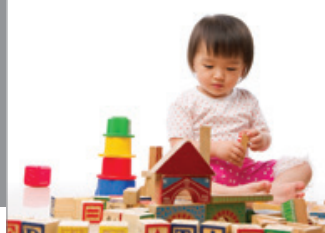

迥
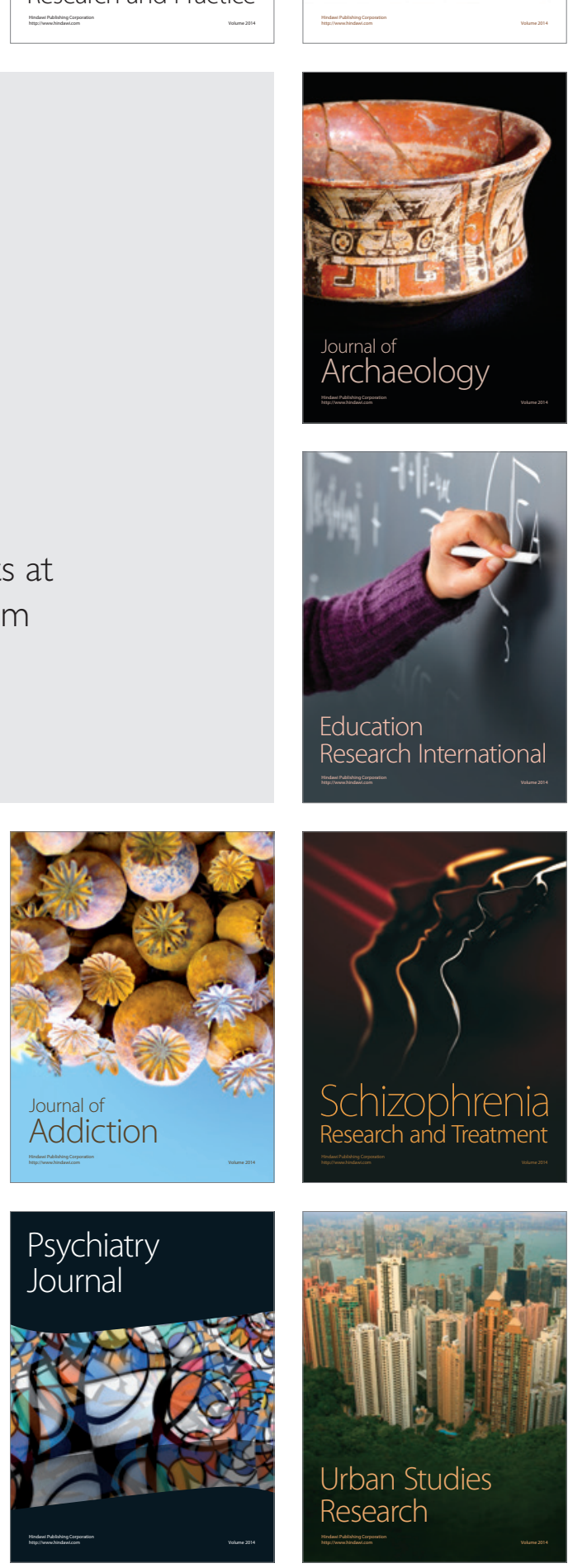